\title{
Informing and Performing: A Study Comparing Adaptive Learning to Traditional Learning
}

\author{
Meg Coffin Murray and Jorge Pérez \\ Kennesaw State University, Kennesaw, GA, USA \\ mcmurray@kennesaw.edu; iperez@kennesaw.edu
}

\begin{abstract}
Technology has transformed education, perhaps most evidently in course delivery options. However, compelling questions remain about how technology impacts learning. Adaptive learning tools are technology-based artifacts that interact with learners and vary presentation based upon that interaction. This study examines completion rates and exercise scores for students assigned adaptive learning exercises and compares them to completion rates and quiz scores for students assigned objective-type quizzes in a university digital literacy course. Current research explores the hypothesis that adapting instruction to an individual's learning style results in better learning outcomes. Computer technology has long been seen as an answer to the scalability and cost of individualized instruction. Adaptive learning is touted as a potential game-changer in higher education, a panacea with which institutions may solve the riddle of the iron triangle: quality, cost, and access. Though the research is scant, this study and a few others like it indicate that today's adaptive learning systems have negligible impact on learning outcomes, one aspect of quality. Clearly, more research like this study, some of it from the perspective of adaptive learning systems as informing systems, is needed before the far-reaching promise of advanced learning systems can be realized.
\end{abstract}

Keywords: Adaptive learning, adaptive learning system, personalized learning systems, iron triangle, informing science.

\section{Introduction}

What is learning? Scholars and philosophers have investigated and debated myriad nuances of this pithy question and will continue to explore it as technology becomes more enmeshed in the human experience. On one hand, we have learned a great deal about learning; on the other hand, learning theories and teaching methods must evolve in concert with our brains as technology mediates our interaction with an increasingly complex, information-rich world.

Material published as part of this publication, either on-line or in print, is copyrighted by the Informing Science Institute. Permission to make digital or paper copy of part or all of these works for personal or classroom use is granted without fee provided that the copies are not made or distributed for profit or commercial advantage AND that copies 1) bear this notice in full and 2) give the full citation on the first page. It is permissible to abstract these works so long as credit is given. To copy in all other cases or to republish or to post on a server or to redistribute to lists requires specific permission and payment of a fee. Contact Publisher@InformingScience.org to request redistribution permission.
Technology has transformed education, perhaps most evidently in course delivery options. However, compelling questions remain about how technology impacts learning. We know that people differ in learning styles and that many other factors affect knowledge acquisition, retention and transfer. Adaptive learning tools are technology-based artifacts that interact with learners and vary presentation based upon that interaction. 
This paper compares adaptive learning with a conventional teaching/learning approach implemented in a digital literacy course.

Myriad theories have evolved to explain the complex interaction between conveyors and recipients of knowledge via various channels: one-to-one versus group instruction, online versus traditional versus hybrid courses, technology-enhanced versus human-guided, and so on. One such body of work, informing science theory, posits that an individual's multifaceted information needs interact with task requirements in the milieu of informer, channel, and receiver -- dynamics that mirror any learning situation. For example, within the informing science paradigm, knowledge transfer occurs as informer, channel, and receiver interact in a complex environment (Cohen, 2009). In this context, adaptive learning is clearly an informing science that will garner significant attention among practitioners, researchers, and educators of all disciplines as foundational technologies evolve.

A primary objective of formal education is to create effective and efficient learning environments. In higher education, the classic learning environment centers on a one-size-fits-all model. Wauters, Desmet and Van den Noortgate (2010) refer to this as a "static" environment, one in which each learner is provided with "the same information in the same structure using the same interface" (p. 549). The application of technology has facilitated more dynamic learning environments. In fact, the promise of technology has generated a new vision - that of intelligent personalized learning environments that facilitate real-time dynamic mapping and sequencing of instruction to individual learner characteristics. The platforms underlying these systems rely heavily on artificial intelligence and complex learning algorithms. Still simplistic in nature, these nascent systems suggest that we are years away from intelligent technology-based learning environments. That said, advances have been made, and personal learning environments are evolving rapidly via implementation of adaptive learning. Tyton Partners, formerly known as Education Growth Advisors, is a leading investor in the education marketplace. They define adaptive learning as "an approach to creating a personalized learning experience that employs a sophisticated data-driven, often non-linear approach to instruction and remediation." Adaptive learning systems, the authors note, "adjust to a learner's interactions and demonstrated performance level, and subsequently anticipate types of content and resources learners need at a specific point in time to make progress" (Tyton Partners, 2013a, p. 4).

\section{Adaptive Learning Theory}

Educators have long known that learning is improved when instruction is personalized -- adapted to individual learning styles. In fact, some argue that advocacy for adaptive instruction dates back to antiquity (Lee \& Park, 2008). Modern views of adaptive learning theory, however, are rooted in the work of contemporary educational psychologists. Cronbach (1957) theorized that learning outcomes are based on the interaction between "attributes of person" and treatment variables. He advocated for differentiating instruction (treatment) to a person's cognitive aptitude. The findings of his early research were inconsistent, leading him to surmise that unidentified interactions existed. His original hypothesis forms the foundation for adaptive learning; he subsequently extended his model to include cognition and personality (Cronbach, 1975). Educators should, he states, "find for each individual the treatment to which he can most easily adapt" (Cronbach, 1957, p.679).

Bloom (1971) theorized that achievement gaps between students could best be addressed by differentiating instruction. To this end, Bloom devised the instructional strategy known as mastery learning, wherein content and skills to be learned are organized into individual units. These modules are presented to students in a period of initial instruction, after which a formative assessment is conducted. The assessment feedback identifies where remedial instruction is needed. Corrective activities are implemented and the assessment-feedback-corrective activities cycle 
continues until mastery is achieved. Bloom (1984) demonstrated that mastery learning via oneon-one instruction results in significant learning gains over conventional group instruction. Learning gains were attributed to the adjustments in instruction made by tutors as they assessed learner progress. Bloom believed that all students could achieve at a high level if provided with appropriate learning conditions that adapt instruction to learning rates and learner modalities.

Current research explores the hypothesis that adapting instruction to an individual's learning style results in better learning outcomes (Pashler, McDaniel, Rohrer, \& Bjork, 2008). Consensus on a definition of learning style is elusive, as myriad distinct learning style models and inventories are extant. However, learning styles are commonly defined as "a set of cognitive, emotional, characteristic and physiological factors that serve as relatively stable indicators of how a learner perceives, interacts with, and responds to the learning environment" (Keefe, 1979, p. 1). Learning styles encompass preference for information type (concrete versus abstract), presentation style (visual, auditory, or kinesthetic) and learning action (active versus reflective). The vast academic literature on learning styles is peppered with few robust experimental studies (Akbulut \& Cardak, 2012; Pashler et al., 2008), and the scarce research outcomes are mixed on the effectiveness of adapting instruction to learning style. Studies do consistently demonstrate that students are able to identify their own learning preferences (Pashler et al., 2008) and that adapting learning conditions to these preferences increases student satisfaction (Akbulut \& Cardak, 2012). The general acceptance of learning styles is evidenced in recommended teaching strategies in nearly every discipline, and learning styles continue to inform the evolution of adaptive learning systems.

Adaptive learning theory can be conceptualized within the informing science theory framework. In this light, an adaptive learning system can be seen as an expression of an informing system wherein the informer is the instructor, the client is the student, and the rule-based adaptive engine both informs and is informed by interaction with the client. Other parallels exist such as learning model to client complexity, domain model to informer context, and adaptation model to the channel. Figure 1 encapsulates the operational implementation of an adaptive learning system within an informing science framework.

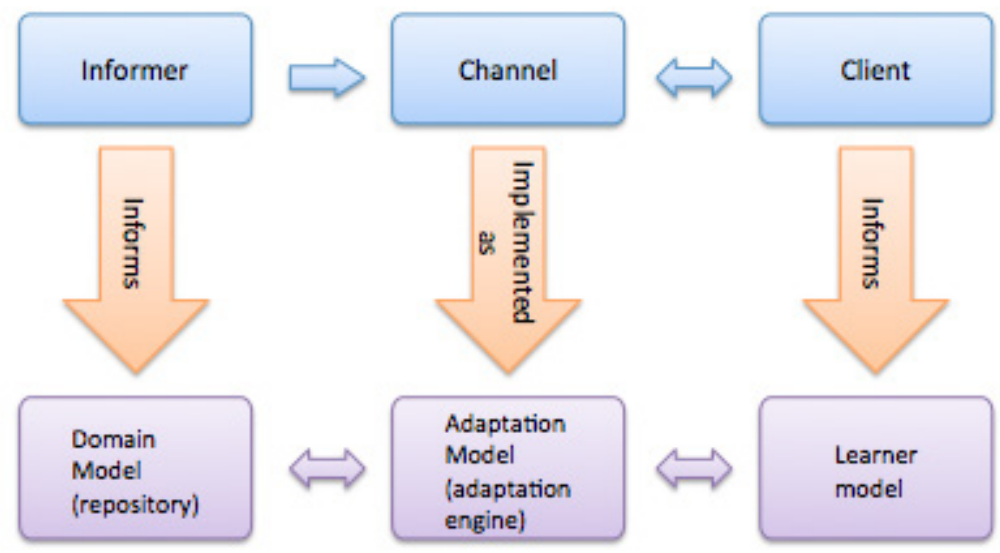

Figure 1: Adaptive Learning System within an Informing Science Framework

\section{Adaptive Learning Systems}

Computer technology has long been seen as an answer to the scalability and cost of individualized instruction. Experimentation with technology-supported instructional guidance emerged in the 1970s in the form of computer assisted instruction (CAI). Based on student responses, these rule-based systems interactively modified the sequence of progression through a series of ques- 
tions. These systems gave way to a category of intelligent learning systems known as intelligent tutoring systems (ITS). These computer-based systems employ artificial intelligence to emulate the teacher-guided learning experience, adjusting instructional strategies based on interaction with students. The systems incorporate the three major components of the learning process: delivery of content, implementation of instructional strategies, and assessment of learning. Although paths through an ITS may differ, the same instructional strategies are presented to all students. Adaptive learning systems (ALS), on the other hand, "attempt to be different for different students" (Brusilovsky \& Peylo, 2003, p. 157). Adaptive learning systems change (adapt) key functions such as content presentation or workflow based on how students interact with content presented by the system. Other forms of ALS are emerging that take non-linear approaches to remediation and presentation. Highly adaptive systems, exemplified by adaptive hypermedia systems (AHS), have contributed most to recent advances in ALS.

\section{Levels of adaptation}

Adaptive learning systems represent a plethora of pedagogical and technological approaches that are difficult to categorize. Lee and Park (2008) delineate ALSs by instructional level. At the macro-level, instruction is adapted by altering instructional goals, delivery systems, or curriculum, enabling adaptation at many dimensions including navigation, assessment, and presentation. Examples include platforms that support instructor creation and development of adaptive learning environments. Mid-level systems facilitate the adaptation of instructional strategies. A simple example of these systems is one that modifies content presentation by medium (audio, visual, video) based on learning preferences indicated by students. At the micro-level, instruction is adapted in real-time as student learning needs are diagnosed and instructional treatments prescribed. These systems employ on-task measurements of student behavior, such as response errors and response latencies, which result in variation of the amount or sequence of content presented to the student.

\section{ADAPTIVE TAXONOMY OVERVIEW EXAMPLE SOLUTION}

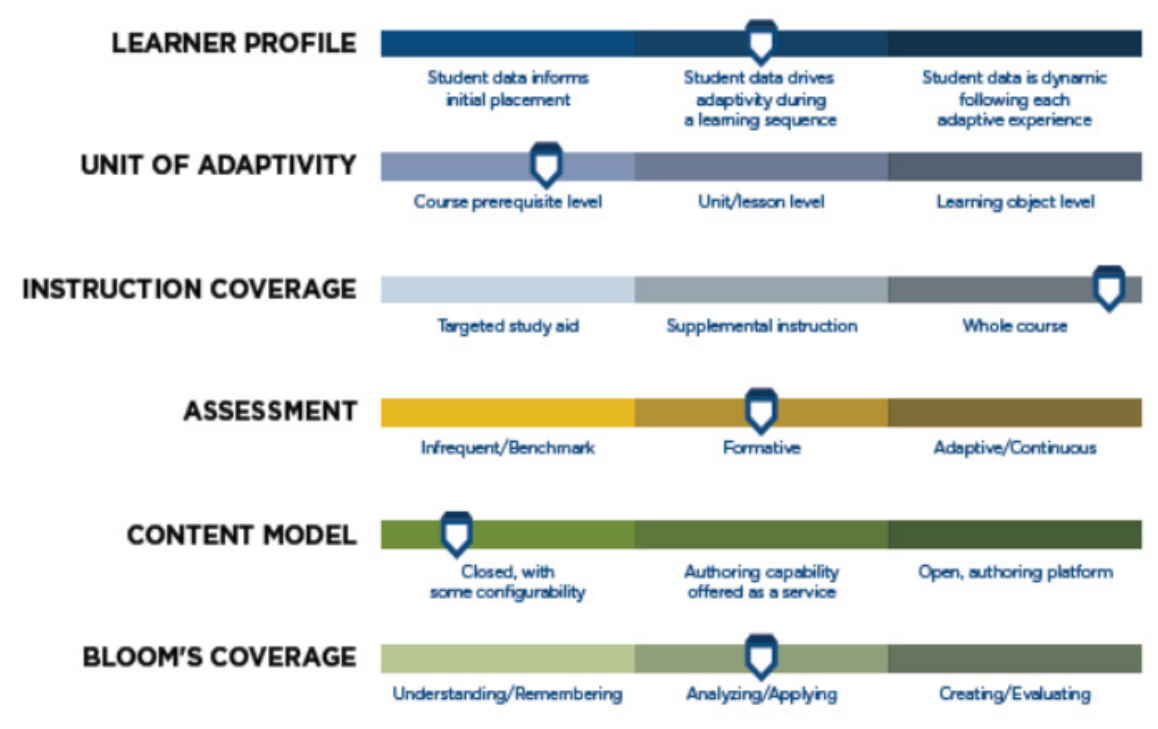

Figure 2: EGA Classification Scheme for Adaptive Learning Solutions

Image from: Tyton Partners (2013b, p. 7). 
Tyton Partners (2013b) proposed an ALS classification scheme based on a taxonomy of six attributes characteristic of an adaptive learning solution (Figure 2): learner profile, unit of additivity, instruction coverage, assessment, content model and "Bloom's coverage." Learner profile captures learner traits and how often traits are tracked and updated. Pedagogical components include the unit of adaptivity denoting the targeted curricular scope, instruction coverage denoting the targeted instructional scope, and Bloom's coverage denoting the targeted level of instruction. Assessment refers to how often a learner is evaluated, and content model refers to the authoring capability provided within the ALS. The taxonomy represents attributes along a continuum of sophistication, with an indicator marking the level of sophistication of a generic ALS. It can be argued that most adaptive learning systems available today are generally less sophisticated, along each continuum, than the average indicator for each dimension.

\section{Adaptive learning system framework}

Technical implementations of adaptive learning systems are also diverse but share a common framework comprised of three models: learner model, domain model, and adaptation model. The learner model is a representation of relevant learner characteristics such as personal information, cognitive traits, knowledge level, and learning preferences. The omnipresent learner model defines the parameters upon which instructional adaptation occurs and is responsible for obtaining and maintaining an accurate representation of learner characteristics. A static model initializes learner attributes once; a dynamic model continuously updates learner attribute values. Learner characteristics may be obtained explicitly through means such as assessment instruments and student questionnaires or implicitly through tracking student interactions with the system. A robust learner model incorporates multiple attributes of learning (Popsecu, Badica \& Moraret, 2010), provides mechanisms to diagnosis and infer learner characteristics (Brusilovsky \& Peylo, 2003) and provides mechanisms for assessing student performance (Lee \& Park, 2008).

The domain model is concerned with representation and organization of knowledge in a specific realm. Through the mapping of learning resources such as content, tasks, activities, assessments, or other learning objects to educational goals, the domain model defines what is to be adapted. The most important aspects of the domain model are the decomposition of knowledge into individual elements of learning (Magoulas, Papanikolaou \& Grigoriadou, 1999), and the specification of the relationships between those elements (Esichaikul, Lamnoi \& Bechter, 2011). The domain model is implemented as a repository of learning resources described by a set of metadata. The metadata contains various traits, including physical characteristics (media type, format, location, etc.), knowledge characteristics (knowledge type, difficulty level, etc.) instructional role (such as defined in Bloom's taxonomy), and relationship specifications (hierarchical, peer, etc.). A strong repository is comprised of a rich collection of materials that represent variety in type, format and instructional method.

The adaptation model is the expression of an instructional strategy defining when and how adaptation occurs. Through an analysis of learner characteristics, associated learning resources are assembled and delivered to the learner. Most adaptation engines are implemented as rule-based systems but numerous adaptation algorithms exist. For example, some engines employ item response theory (Wauters et al., 2010), while others incorporate machine learning or artificial intelligence (Magoulas et al., 1999). The interplay between the adaptation model and the learner model is critical; "the result of the adaptation process can only be as accurate and comprehensive as the underlying student [learner] model" (Popsecu et al., 2010, p.454).

Current implementations of adaptive learning systems vary in sophistication. The most rudimentary systems incorporate straightforward rule-based architectures. A common use of rudimentary systems is to reinforce basic math skills. For example, a student is given a mathematical problem to solve. If answered correctly, a more difficult problem is presented. An 
incorrect response, on the other hand, results in the presentation of either an easier problem or additional instruction.

A more sophisticated adaptive learning system adjusts the presentation of instructional materials based on assessment of the user's understanding of concepts -- abstractions or general ideas about what something is or how it works. An adaptive learning system that evaluates conceptual understanding incorporates complex diagnostics and data-driven algorithms. For example, a student learning the concept of uncertainty in physics is presented with several quiz questions. The student's responses are compared to the responses of other students who have used the program to assess deficiencies in conceptual understanding. The student is then presented learning materials focused on knowledge points on which she is deficient. More comprehensive learning systems actually adapt the student's learning environment via multiple sets of instructional objects that reflect teaching methods such as videos, animations, simulations, and case studies. In essence, the student's learning path is guided by not only performance but also by the system's inference of preferred learning style.

\section{Research Question}

Adaptive learning has been cast as a pedagogical renaissance that has the potential to enable institutions of higher education to disentangle the iron triangle of quality, access, and cost (Jarrett, 2013; Zimmer, 2014). This study poses the questions: How does adaptive learning compare with conventional instruction? What is the impact of adaptive learning on learning outcomes? Does adaptive learning influence student engagement with course content? The rate at which commercially available adaptive learning systems are being adopted by institutions of higher education creates an imperative among scholars to explore questions such as these. The promise of adaptive learning to transform education is sounded in a growing body of literature; explorations such as the one described in this paper are rare.

\section{The Study}

This study examines and compares two instructional methods used to promote and monitor student engagement with textbook content in a university-level digital literacy course delivered in an asynchronous online format. The first method adopted a set of interactive exercises that were part of an adaptive learning product designed and developed by the publisher of the textbook used in the course. The product can be categorized as a micro-level adaptive learning system, wherein instruction and tasks are adapted in real time. The second method employed a more traditional approach in which students were assigned a set of quizzes comprised of objective items drawn from a test bank supplied by the textbook publisher. Supplemental instruction covering textbook material was not provided to the students in either approach. This study examines completion rates and exercise scores for students assigned adaptive learning exercises and compares them to completion rates and quiz scores for students assigned objective-type quizzes. Finally, student test scores on comprehensive exams were analyzed.

The study covered a period of two academic semesters during which 105 students enrolled in an introductory digital literacy course featuring adaptive learning exercises and 113 students enrolled in a course using objective-type quizzes. The course was divided into modules focused on specific topics; eleven of the modules incorporated an adaptive learning exercise or quiz. The exercises and quizzes were mapped to individual modules that corresponded to a particular chapter or section in the textbook. All sections of the course covered the same content, had identical learning outcomes, and were taught by the same instructor to minimize extraneous variance. An electronic version of the textbook was selected for use; no students opted to purchase a hard copy version of the text that was available at an additional cost. Course topics included computer 
hardware, digitization, operating systems, software life cycle, programmatic logic, telecommunications, database technology, information literacy, computer security, internet technologies, and web page development.

Open to all students at the university, the digital literacy course is not targeted at any specific discipline. Rather, the course is positioned as a core option in a liberal arts general education curriculum typical of undergraduate degree programs in the United States. Students from many different majors and at various levels in their program of study enrolled in the course. Table 1 presents demographics of students who participated in the study.

Table 1. Student Demographic Data

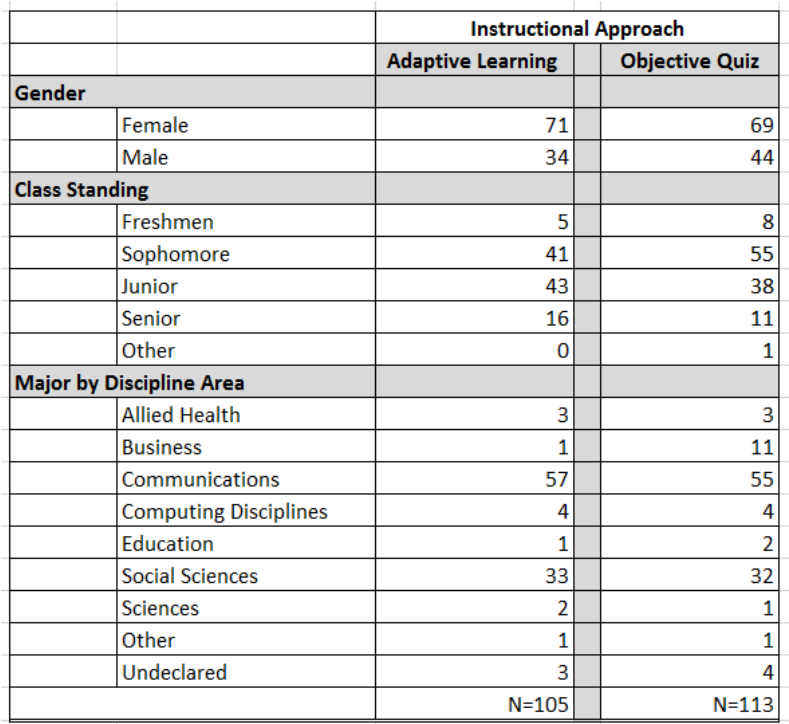

\section{Adaptive Learning Method}

Students were assigned 11 different interactive exercises in an adaptive learning product developed by the textbook publisher. The adaptive learning system is comprised of a set of questions of varying formats including multiple choice, matching, and fill-in-the-blank. The questions and formats are very similar to items included in the publisher's test bank. In the adaptive learning product used in this study, questions were organized by content into learning units. A specific concept or vocabulary term is an example of a learning unit. Multiple questions, varying in question-type or wording, are associated with each learning unit, and an adaptive learning exercise is a compilation of learning units.

In this adaptive learning product, students are presented with a question and asked to indicate confidence in their ability to successfully answer that question. They are provided with four choices: I don't know, Think so, Unsure, and No idea. Students are given the opportunity to answer the question or "Give up." A student response of "No idea" or "Give up" results in the display of the correct answer but the learning unit is marked as not-complete. If a student chooses to answer a question, immediate feedback is provided and the correct answer is identified, regardless of the student's response. Figure 3 provides an example question and subsequent feedback when an incorrect response is given. 

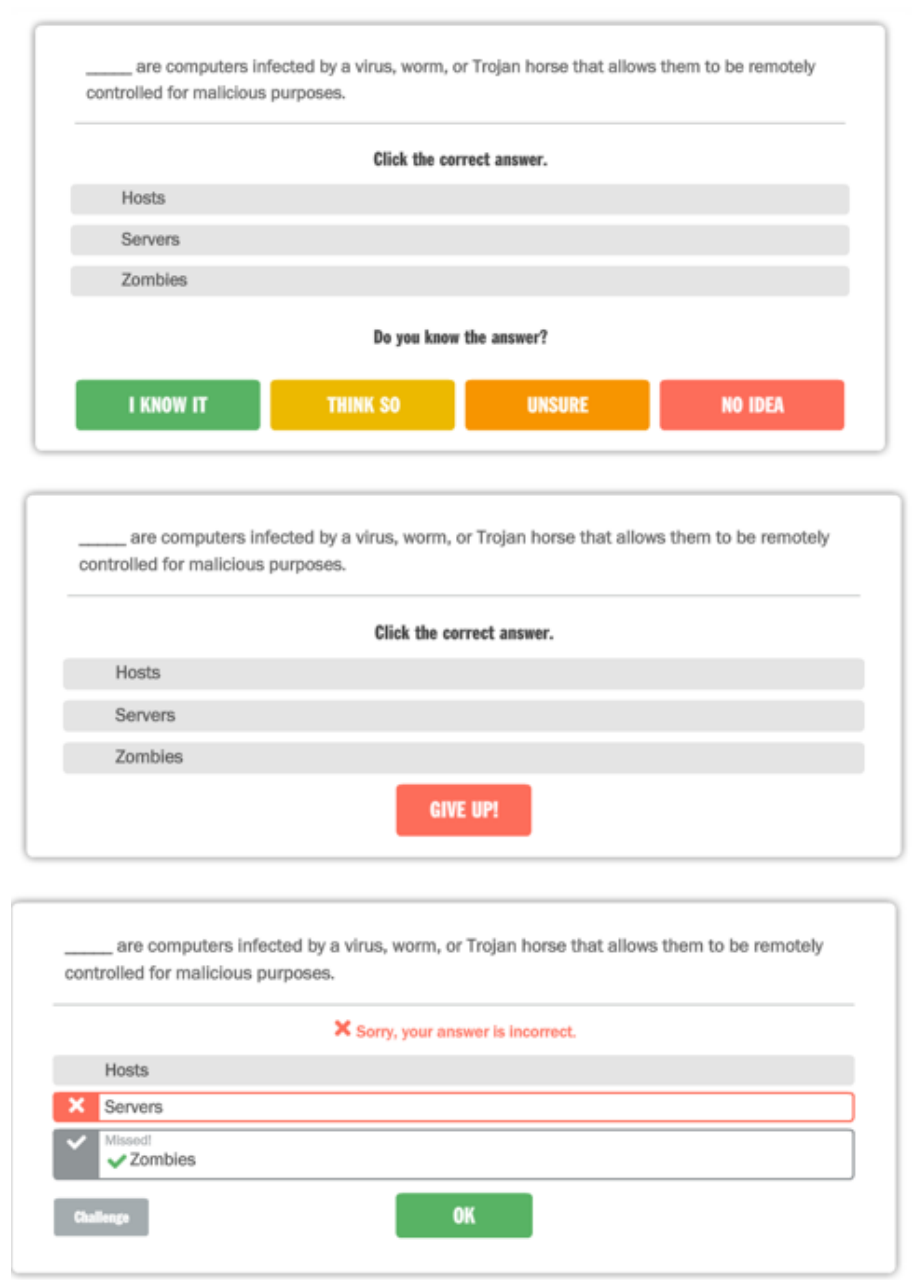

Step 1: Students are asked to indicate their knowledge level.

\section{Step 3: Students are given feedback. The correct answer is identified.}

\section{Figure 3: Sample question and answer feedback from an adaptive learning product Image from: McGraw-Hill Education (2015).}

Successful completion of a learning unit is determined based on two factors: correct answers and student degree of confidence in the ability to correctly answer a question. An incorrect response prevents a learning unit from being marked as complete, and additional questions related to that learning unit will be presented to the student at a later time. The follow-on questions are interjected randomly, rather than sequentially, as a student progresses through the exercise. In most cases, a confidence indication of "unsure" prevents a learning unit from being marked as complete. However, this is not always the case. For example, multiple correct responses may result in successful completion of a learning unit regardless of the confidence level indicated by a student. The exact set of responses that triggers unit completion is proprietary to the adaptive learning product. Student progress is based on the number of units successfully completed, and scores are recorded as the percentage of units successfully completed before the assignment deadline.

Student completion rates for the adaptive learning exercises were high; most students attempted a majority of the exercises. More than $63 \%$ of the students attempted all assignments, and $95 \%$ attempted at least eight of the 11 exercises. Only one student did not attempt any assignment and only four students attempted seven or fewer exercises. It should be noted that non-attempts were evenly distributed across exercises. Figure 4 depicts student attempts by adaptive learning exercise and Table 2 reports percentage of exercises attempted. 


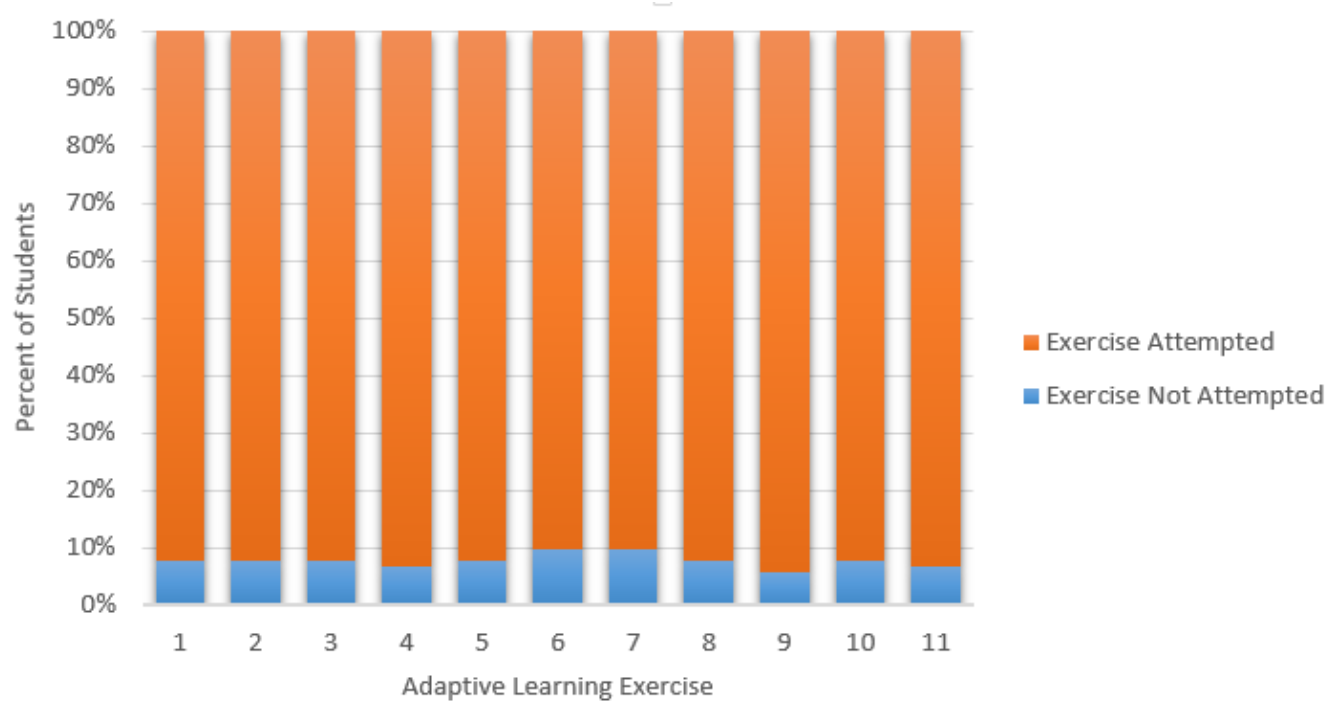

Figure 4. Student attempts by adaptive learning exercise

Table 2. Number of adaptive learning exercises attempted by students

\begin{tabular}{|r|r|r|}
\hline $\begin{array}{c}\text { Number of Exercises } \\
\text { Attempted }\end{array}$ & \multicolumn{2}{|c|}{ Students } \\
\hline 11 & Frequency & Percent \\
\hline 10 & 16 & $63.8 \%$ \\
\hline 9 & 12 & $15.2 \%$ \\
\hline 8 & 5 & $11.4 \%$ \\
\hline 7 & 1 & $4.8 \%$ \\
\hline 6 & 1 & $1.0 \%$ \\
\hline 5 & 1 & $1.0 \%$ \\
\hline 4 & 1 & $1.0 \%$ \\
\hline 3 & 0 & $1.0 \%$ \\
\hline 2 & 0 & $0.0 \%$ \\
\hline & & $0.0 \%$ \\
\hline
\end{tabular}

Scores on individual exercises were exceptionally high. The mode score for all completed assignments for all students on all exercises was 100 . For the most part, a student who attempted an exercise successfully completed all learning units in that exercise. For example, 97 students attempted the first adaptive learning exercise, and all 97 students successfully completed all items associated with it. This pattern remained consistent throughout the course. On the last assigned adaptive learning exercise, 97 of 98 students who attempted the exercise completed all units therein. Only $83 \%$ of students who attempted adaptive learning exercise 8 completed all units in the exercise, the lowest completion rate among exercises. Figure 5 shows the percent of items completed by each student on the adaptive learning exercises. Not attempted, quartile ranges and $100 \%$ completion rates are represented by different colored bars grouped by adaptive learning 
exercise. The bar to the left of each grouping indicates the percentage of students who did not attempt the exercise; the bar to the right indicates the percentage of students who completed all learning items. A gap indicates no student scores in that quartile range. Non completion rates in the $51-75 \%$ range were not reported for any adaptive learning exercise.

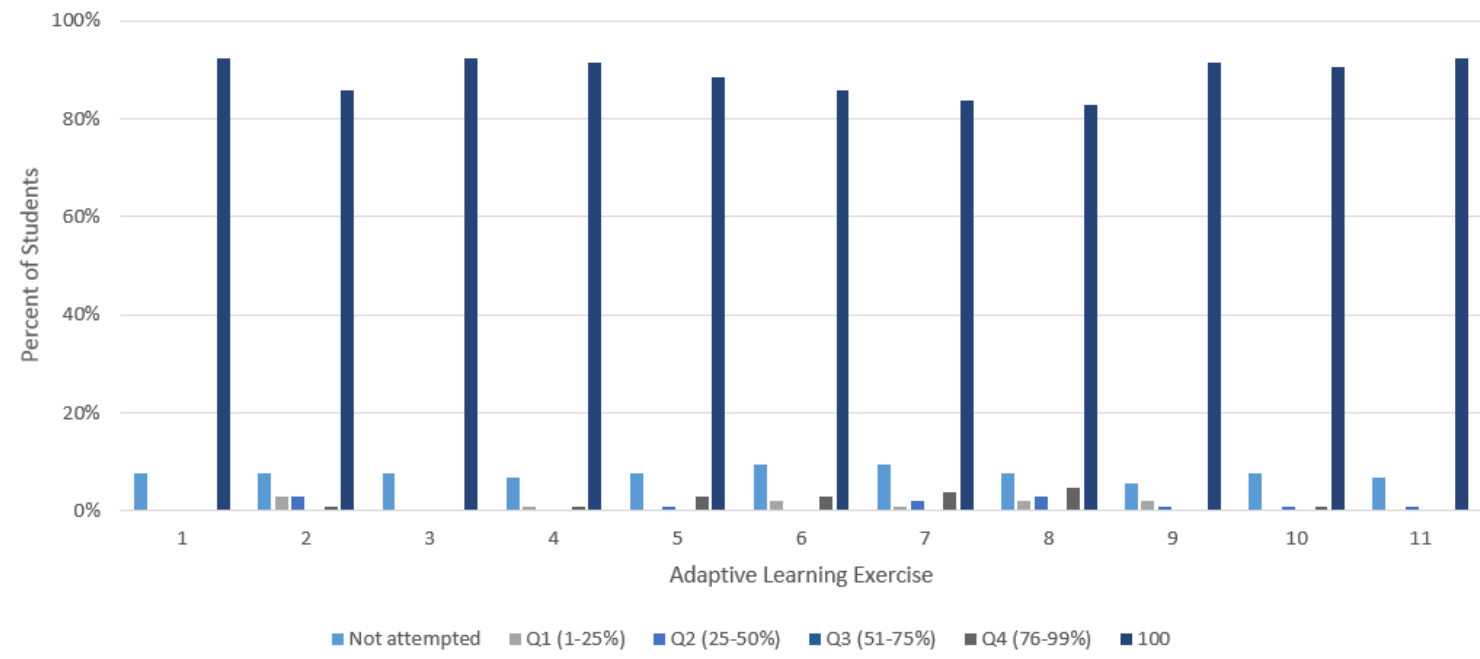

Figure 5. Student scores by adaptive learning exercise

The instructor assessed student learning via two objective exams, one after module 5 and another after module 11. The average test scores on the first exam and second exam were 84.38 and 85.11, respectively. A plot of student adaptive learning exercise scores (x-axis) against exam scores (y-axis) for both exams appears in Figure 6. The graphs exhibit a similar pattern of vertical clusters that depict variation in exam scores for a specific exercise score. For example, the cluster on the right side of the $\mathrm{x}$-axis represents the various exam scores students received, even though those same students successfully completed $100 \%$ of the adaptive learning exercises. While a positive correlation existed between adaptive learning exercises and exam scores, it was only slightly significant on the first exam $\left(\mathrm{r}=.33,{ }^{*} \mathrm{p}<.05\right)$, and not significant on the second exam $(\mathrm{r}=.133)$. It is noteworthy that student achievement on the adaptive learning exercises was not necessarily indicative of their performance on exams.
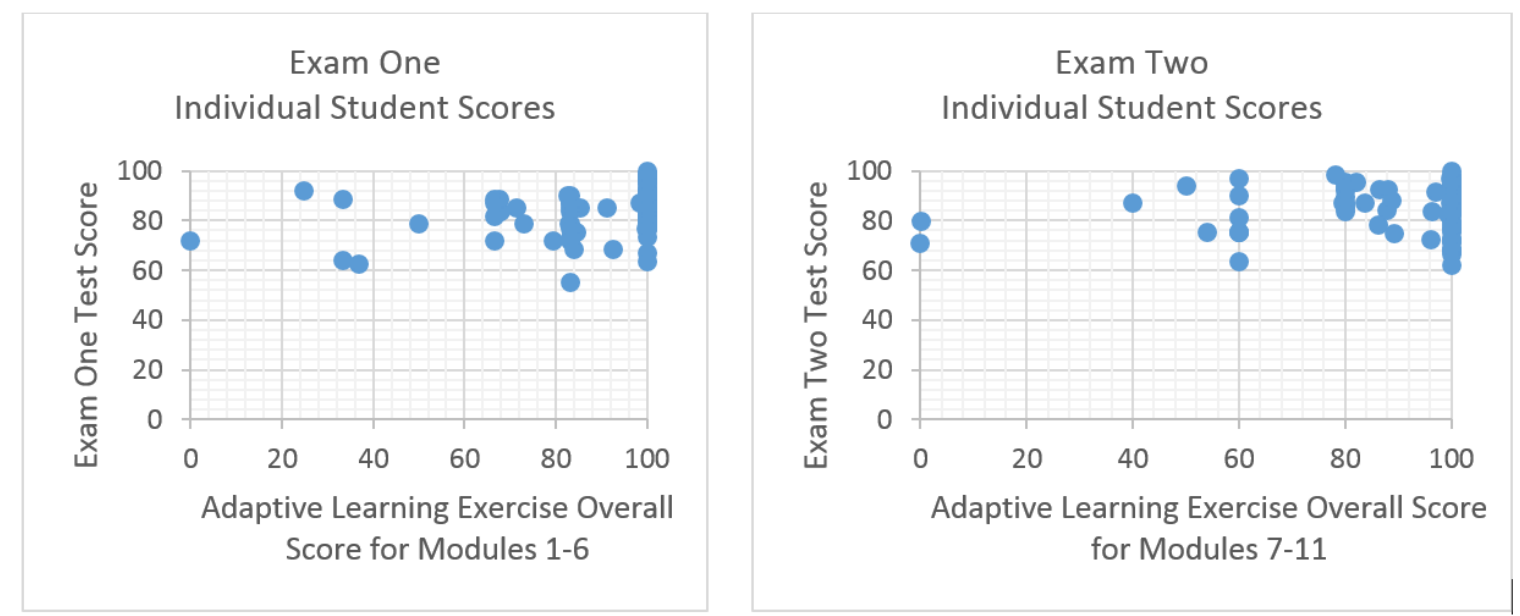

Figure 6. Student exam scores plotted against adaptive learning exercise scores 


\section{Objective-type Quiz Method}

Using an approach similar to the strategy used in the adaptive learning method, students in the objective-type quiz method were assigned 11 different quizzes. Multiple choice, matching and true/false quiz questions were drawn from the test bank provided by the textbook publisher. The number of items per quiz ranged from 21 to 25 . As in the adaptive learning course section, students were directed to read the textbook material and then take the quiz. In contrast, students in this section took quizzes via an online course management system. Students were given one week to complete each quiz, but each quiz did not have a time limit for completion. During the period the quiz was available, students were able to access the quiz as often as desired and change their answers. However, once a quiz was submitted, answers could not be modified.

Most students attempted a majority of the quizzes, and more than $67 \%$ of the students completed all quizzes. The fewest number of quizzes attempted by any student was 4 . Figure 7 depicts the percentage of students who completed each quiz, and Table 3 shows the percentage of quizzes taken by each student.

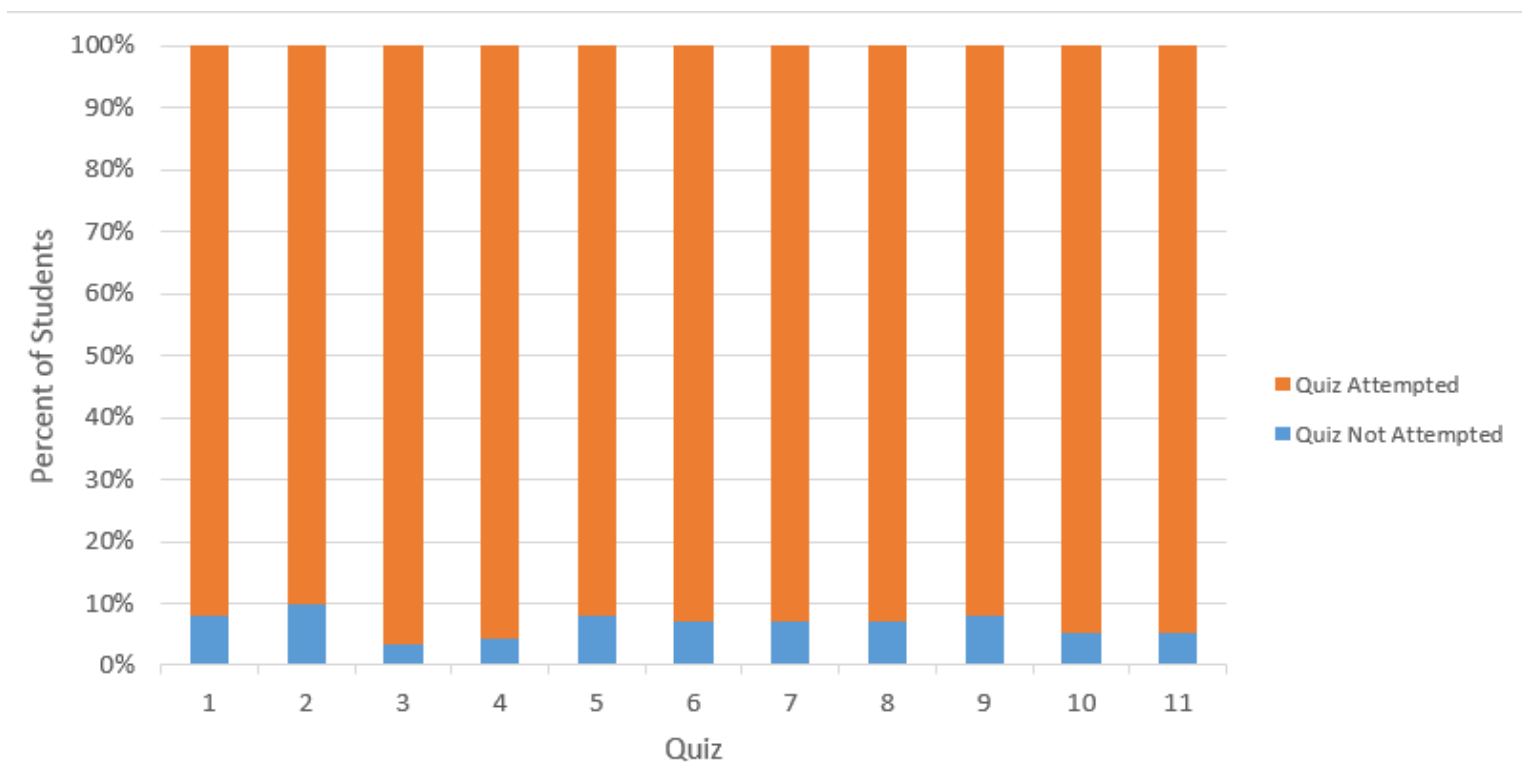

Figure 7. Student attempts by quiz

Table 3. Number of quizzes attempted by students

\begin{tabular}{|r|r|r|}
\hline \multirow{2}{*}{ Number of Quizzes Attempted } & \multicolumn{2}{|c|}{ Students } \\
\hline & Frequency & \multicolumn{1}{c|}{ Percent } \\
\hline 11 & 76 & $67.3 \%$ \\
\hline 10 & 18 & $15.9 \%$ \\
\hline 9 & 10 & $8.8 \%$ \\
\hline 8 & 4 & $3.5 \%$ \\
\hline 7 & 2 & $1.8 \%$ \\
\hline 6 & 1 & $0.9 \%$ \\
\hline 5 & 1 & $0.9 \%$ \\
\hline 4 & 1 & $0.9 \%$ \\
\hline 3 & 0 & $0.0 \%$ \\
\hline 2 & 0 & $0.0 \%$ \\
\hline 1 & 0 & $0.0 \%$ \\
\hline 0 & 0 & $0.0 \%$ \\
\hline & & \\
\hline
\end{tabular}


Average quiz scores ranged from 69 to 82 out of a possible 100 points. Within that consistency, scores of each individual student varied significantly on the 11 quizzes, as depicted in Figure 8, in which each bar represents a range of scores. The height of the bar indicates the percentage of students achieving a score in that range. Scores were organized using a traditional A, B, C, D and F grading scale of 90-100, 80-89, 70-79, 60-69 and less than 60 . The bar to the left of each quiz grouping represents students who did not attempt the quiz; the bar to the far right represents students earning the highest grades. The average quiz score appears above each grouping. The majority of students scored above 70 on all quizzes. On the first quiz, which covered introductory material, half of the students scored in the highest possible range. Scores were much lower on the second, fifth and ninth quizzes. The uneven distribution of quiz scores is intriguing since quizzes were untimed, providing students with the opportunity to verify their answers.

\begin{tabular}{|c|c|c|c|c|c|c|c|c|c|c|c|c|}
\hline & & & & & & Quiz & & & & & & \\
\hline & Q1 & & Q2 & Q3 & Q4 & Q5 & Q6 & Q7 & Q8 & Q9 & Q10 & Q11 \\
\hline Average Score & & 82.3 & 70.8 & 81.7 & 79.1 & 71.0 & 74.6 & 77.3 & 81.2 & 69.1 & 79.8 & 82.1 \\
\hline
\end{tabular}

$60.0 \%$

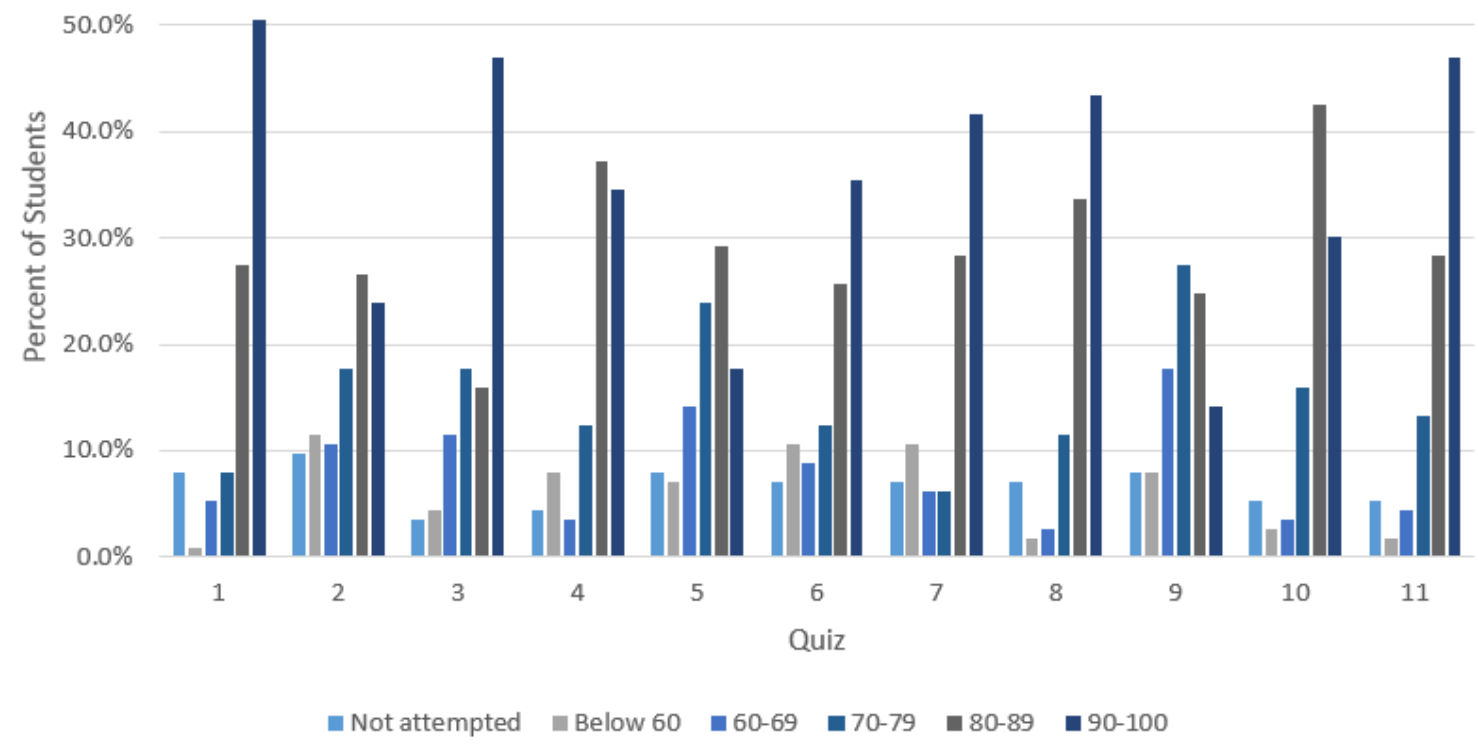

Figure 8. Student scores by quiz

The instructor assessed student learning via an objective exam given after modules 5 and 11, as in the adaptive learning course sections. The average test scores on the first and second exams were 84.13 and 83.15, respectively. A plot of student overall average quiz scores (x-axis) against exam scores (y-axis) for both exams is depicted in Figure 9. Exam scores tended to be higher than average quiz scores. On the first exam, $69 \%$ of the students had higher exam scores than average quiz scores. On the second exam, 58\% had higher exam scores. A positive but weak correlation exists between quiz scores and exam scores (exam 1: $\mathrm{r}=.29,{ }^{*} p<.05$; exam 2: $\mathrm{r}=.25,{ }^{*} p<.05$ ). If students did well on the quizzes, they were likely to do well on the exams; on the other hand, students with low quiz scores often also did well on the exams. 

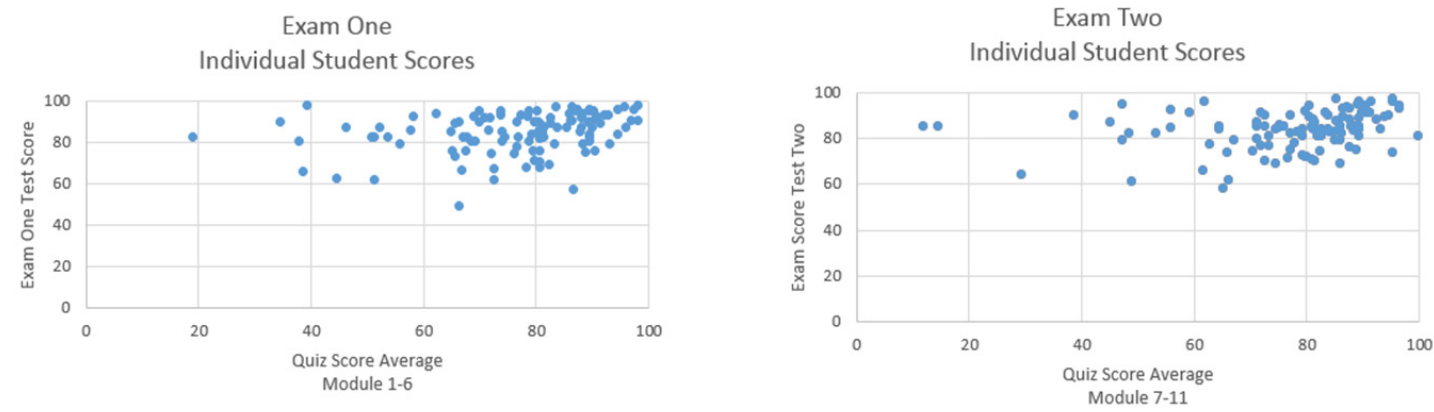

Figure 9. Student exam scores plotted against quiz scores

There was no significant difference in test scores between students enrolled in courses using adaptive learning and traditional instruction. Results of a t-test comparing exam scores across methods for the first exam $(* * * p<.001)$ and the second exam $(* * * p<.001)$ were not significant. A graph of individual student test scores for each exam for both groups of students is presented in Figure 10. The data overwhelmingly supports the conclusion that neither the adaptive learning approach nor the traditional, objective quiz approach provided a definitive learning advantage.

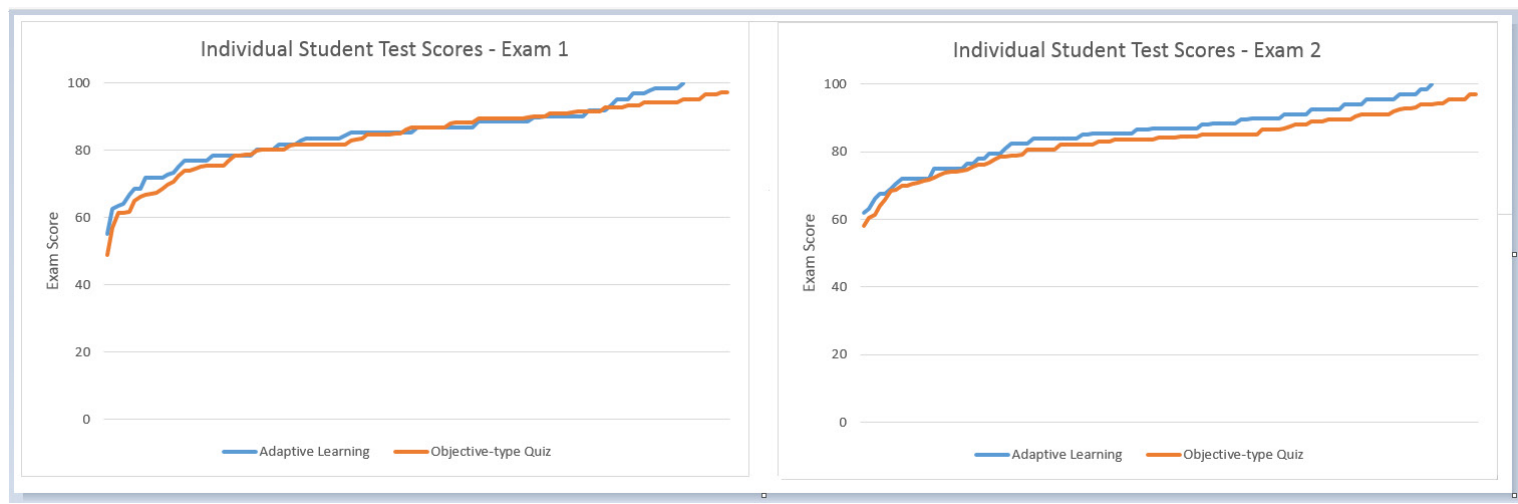

Figure 10. Student exam by instructional method

\section{Conclusion}

Adaptive learning is touted as a potential game-changer in higher education, a panacea with which institutions may solve the riddle of the iron triangle: quality, cost, and access. Though the research is scant, this study and a few others like it indicate that today's adaptive learning systems have negligible impact on learning outcomes, one aspect of quality. There is also evidence that adaptive systems positively impact other aspects of quality such as student persistence and engagement (Jarrett, 2013; Zimmer, 2014). More compelling still are the intuitively appealing cases for adaptive learning systems as engines with which institutions can increase access and reduce costs. One cautionary note that arises from these dynamics is the danger that educational institutions will, in the throes of ongoing waves of online learning, dismantle the triangle by relying on adaptive learning to cut costs and increase access without paying due attention to quality. These dynamics illuminate one way that the informing science framework can serve as a lens through which to explore the evolution of adaptive learning systems.

This study compared an adaptive learning system with a traditional objective assessment approach to instructional content delivery and assessment in a digital literacy course. Findings indicate that student learning, gauged via two examinations, did not vary significantly across the 
courses based upon instructional delivery approach. This presents an interesting proposition for university leaders who are under increasing pressure, as noted above. Technology will continue to advance at a blinding pace; the note of caution that we must sound is that pedagogy, rather than technology, must drive the evolution of advanced learning systems. Clearly, more research like this study, some of it from the perspective of adaptive learning systems as informing systems, is needed before the far-reaching promise of advanced learning systems can be realized.

\section{References}

Akbulut, Y., \& Cardak, C. S. (2012). Adaptive educational hypermedia accommodating learning styles: A content analysis of publications from 2000 to 2011. Computers \& Education, 58, 835-842.

Bloom, B. S. (1971). Mastery learning. In J. H. Block (Ed.), Mastery learning: Theory and practice (pp. 47-63). New York: Holt, Rinehart \& Winston.

Bloom, B. S. (1984). The 2 sigma problem: The search for methods of group instruction as effective as one-to-one tutoring. Educational Researcher, 13(6), 4-16.

Brusilovsky, P., \& Peylo, C. (2003). Adaptive and intelligent web-based educational systems. International Journal of Artificial Intelligence in Education, 13(2-4), 159-172.

Cohen, E. (2009). A philosophy of informing science. Informing Science: the International Journal of an Emerging Transdiscipline, 12, 1-15. Available from http://inform.nu/Articles/Vol12/ISJv12p001015Cohen399.pdf

Cronbach, L. (1957). The two disciplines of scientific psychology. American Psychologist, 12(11), 671684. Available from http://psychclassics.yorku.ca/Cronbach/Disciplines/

Cronbach, L. (1975). Beyond the two disciplines of scientific psychology. American Psychologist, 30(2), $116-127$.

Esichaikul, V., Lamnoi, S., \& Bechter, C. (2011). Student modeling in adaptive e-learning systems. Knowledge Management \& E-Learning: An International Journal, 3(3), 342-355. Available from http://www.kmel-journal.org/ojs/index.php/online-publication/article/viewFile/124/102

Jarrett, J. (2013). Bigfoot, Goldilocks and moonshots: A report from the frontiers of personalized learning. EDUCAUSE Review. Available from http://www.educause.edu/ero/article/bigfoot-goldilocks-andmoonshots-report-frontiers-personalized-learning

Keefe, J. W. (1979). Learning style: An overview. In Student learning styles — Diagnosing and prescribing programs (pp. 1-17). Reston, VA: National Association of Secondary School Principals.

Lee, J., \& Park, O. (2008). Adaptive instructional systems. In J. M Spector, M. D. Merrill, J. van Merrienboer, \& M. P. Driscoll (Eds.), Handbook of research on educational communications and technology (3rd ed., pp. 469-484). New York: Lawrence Erlbaum.

Magoulas, G. D., Papanikolaou, K. A., \& Grigoriadou, M. (1999). Towards a computationally intelligent lesson adaption for a distance learning course. Proceedings of the 11th IEEE International Conference on Tools with Artificial Intelligence.

McGraw-Hill Education. (2015) LearnSmart Advantage. Available from http://learnsmartadvantage.com

Pashler, H., McDaniel, M., Rohrer, D., \& Bjork, R. (2008). Learning styles: concepts and evidence. Psychological Science in the Public Interest, 9, 105-119.

Popsecu, E., Badica, C., \& Moraret, L. (2010). Accommodating learning styles in an adaptive education system. Informatica, 34, 451-462.

Tyton Partners (2013a). Learning to adapt: A case for accelerating adaptive learning in higher education. [White Paper]. Available from http://tytonpartners.com/library/understanding-the-adaptive-learningsupplier-landscape/ 
Tyton Partners (2013b). Learning to adapt: Understanding the adaptive learning supplier landscape. [White Paper]. Available from: http://tytonpartners.com/library/accelerating-adaptive-learning-inhigher-education/

Wauters, K., Desmet, P., \& Van den Noorgate, W. (2010). Adaptive item-based learning environments based on the item response theory: Possibilities and challenges. Journal of Computer Assisted Learning, 26, 549-562.

Zimmer, T. (2014). Rethinking higher ed: A case for adaptive learning. Forbes Education. Available from http://www.forbes.com/sites/ccap/2014/10/22/rethinking-higher-ed-a-case-for-adaptive-learning/

\section{Biographies}

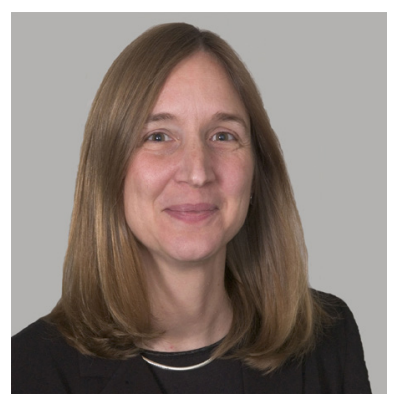

Meg Coffin Murray is a professor of information systems who holds a joint appointment in the Coles College of Business and the University College at Kennesaw State University. She holds a Ph.D. in information systems and has over thirty years of experience in both academe and industry. Dr. Murray specializes in the development and implementation of emerging technologies to meet educational, business and societal needs. Her current work devises strategies to assess, remediate and amplify skills students need to leverage IT in innovation, a primary driver of economic growth.

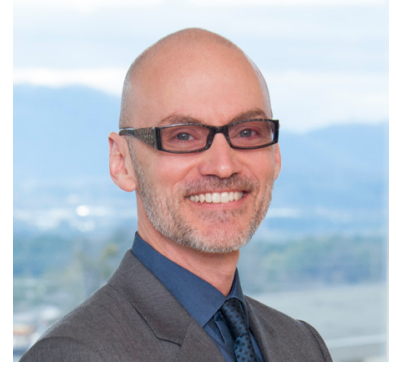

Jorge Pérez is vice provost for institutional effectiveness and professor of information systems at Kennesaw State University. He holds a Ph.D. in information systems from Florida State University and has over two decades of experience as a consultant, systems analyst, web developer and educator. Dr. Pérez has published research on diffusion of innovations, information security, IS education and online learning. He is a 2013-14 American Council on Education (ACE) Fellow whose current research focuses on leadership and digital literacy. 